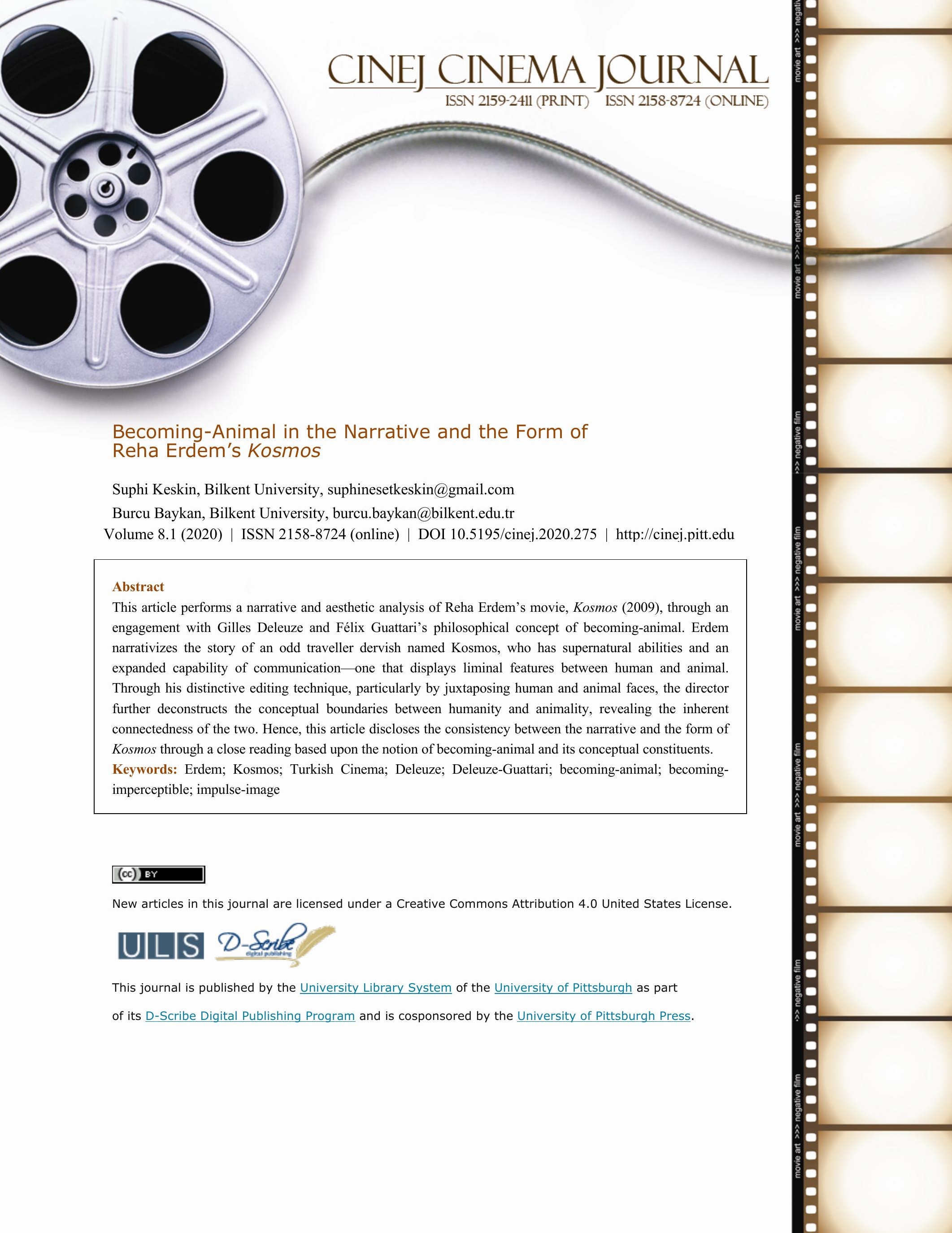




\section{Becoming-Animal in the Narrative and the Form of Reha Erdem's Kosmos}

Suphi Keskin and Burcu Baykan

\section{Introduction}

Reha Erdem has a unique and peculiar place in Turkish cinema due to his distinct cinematography and narratives. According to Murat Akser (2015), he is one of the founding members of Turkish art-house cinema along with Derviş Zaim, Nuri Bilge Ceylan, Zeki Demirkubuz, Semih Kaplanoğlu and Yeşim Ustaoğlu in the 1990s. Among these auteurs, Erdem comes to the fore with his numerous applications of editing, storytelling and genre diversityincluding comedy, apocalypse and war genres - as well as his philosophical grounds. He devices metaphorical and complicated plots with protagonists who display odd, fluid, unstable and mutable characteristics. Indeed, since the inception of his cinema career with Oh Moon (A Ay, 1988), Erdem's movies contain characters who are particularly maladaptive to modern life. Delineated as outsiders of their environment, these characters are in a constant flux of transformation without any sense of social or geographical belonging. Erdem further enhances his stories through an unconventional and distinctive employment of montage sequences. As Akser (2015) states, Turkey's art-house filmmakers follow the aesthetics of European independent cinema, including Erdem who is trained in French film school and employs French crew in his shoots like Florent 
Herry. Beginning with his fourth feature film, Times and Winds (Beş Vakit, 2006), Erdem conforms to this aesthetics by employing long takes and wide shots with static camera placement. Yet, at the same time, he modifies this style via his utilization of short-duration close-ups juxtaposed together in montage sequences. ${ }^{1}$

Erdem's sixth feature film, Kosmos, comes forward with its leading character Kosmos—one of the most complex and idiosyncratic characters in the director's oeuvre-as well as its juxtapositions of long-duration shots with short montage sequences. The narrative flows in two different channels: one channel narrativizes the unusual story of Kosmos, whereas the other consists of the montage sequences that convey the meta-idea of the movie- - human and animal commonality—and intensify the effect of the preceding and the subsequent scenes. This Messiahlike dervish, Kosmos, is a lunatic with supernatural powers. Neither norms and rules of the society, nor the law of nature can restrain this character. He can even fly or move swiftly in a paranormal way. His diet merely consists of drinking tea and eating sugar. Never seen sleeping throughout the movie, Kosmos does not keep a permanent residence. Sometimes he communicates with people through inarticulate and animal-like noises, yet when he speaks in human language, he often talks like an orator. As such, Kosmos is portrayed as a traveller dervish who belongs nowhere, displaying liminal characteristics between man and nature, human and animal. Accordingly, 
Gülengül Altıntaş (2014) rightly characterizes him as a psychologically and geographically "inbetween" character (p. 254)—an ongoing thematic component in almost all Erdem movies.

The movie commences with Kosmos' escape from something or someone while he is crying; then he migrates to a timeless border town where there is a war nearby. In an analogous manner to Erdem's previous films, the protagonist departs from his habitual territory and arrives as a stranger in a new town. Kosmos struggles with the fixed and normative codes of the society due to his aberrant characteristics: he is indifferent to work, settlement and nourishment. As Altıntaş (2014) goes on to suggest, he remains as "a mysterious, saintly character, who has stepped out of the social (the order of humanity)" (p. 254). Indeed, not even carrying an ID card, Kosmos frequently steals money, not only for himself, but also for indigent people. He sustains his life by minimizing his needs, except for one thing: he frankly declares his search for love. His interest in women, particularly Neptune, whose brother is miraculously saved by Kosmos at the onset of the movie, annoys the townspeople. His uncommon and even strange features startle the residents despite his saintly healing power. ${ }^{2}$ Overall, Kosmos emerges as a hero depicted outside of all familiar and recognizable identity categories, settled lifestyles and sedentary values; as a result, the townspeople do not know what to do with him. 
Kosmos' fluid, indeterminate and unclassifiable identity, along with his liminal qualities between man and animal—which are accentuated by the idea of human-animal continuity evoked through the close-ups in the montage sequences - enable a critical analysis of Erdem's movie through the lens of Gilles Deleuze and Félix Guattari’s (1987) concept of "becoming-animal". Hence, this article traces the enactment, animation and mobilization of the notion of becominganimal both in the narrative and the form of Kosmos. Accordingly, its focus is twofold. First, it explores the narrative mainly through studying the narrativization of the film's protagonist and Erdem's allusions to the human-animal connectedness in the montage sequences within the framework of becoming-animal and its intrinsic vocabularies, such as deterritorialization, zone of indiscernibility and becoming-imperceptible (Deleuze \& Guattari, 1987). Second, it delves into the form of the film by discussing the montage sequences in dialogue with Deleuze's ideas on the time-image (2001) and the impulse-image (1997a), the latter of which is interpreted as the realization of becoming-animal in editing (Deamer, 2016). The following section looks more closely at the specific concepts advanced by Deleuze and Guattari-concepts which provide the basis of the narrative and formal analyses of Kosmos. 
The principle of becoming, which entails a dynamic movement, continuous change and never-ending flow, is at the heart of Deleuze's process-oriented philosophy. He, along with his collaborator Guattari, oppose fixed models of being, identity and representation, arguing that existence is not static, but in ceaseless flux. Hence, instead of an ontology of stasis and closure, they promote a more dynamic and open-ended one-an ontology of becoming-which foregrounds the ongoing production of relational interactions between a diverse range of human and non-human phenomena (Deleuze \& Guattari, 1987). Becomings, in this sense, are processes involving the continual transformation of the self and the destabilization of unitary identity structures based on binary logics. Rosi Braidotti (2011) highlights this dimension of the philosophy of becoming, which "functions as a deterritorializing agency that dislodges the subject from his/her sense of unified and consolidated identity" (p. 31), by placing the self in a multiplicity of relations with external forces. Patterns of becoming, as Braidotti goes on to detail, are "about affinities and the capacity both to sustain and generate inter-connectedness" $(2002$, p. 8); thus, they inevitably signal "the overcoming of the dualism Self/Other" (2006b, p. 169).

In A Thousand Plateaus: Capitalism and Schizophrenia (1987), Deleuze and Guattari define specific modalities of their ontology of becoming, including becoming-animal. Their philosophy, which questions all rigid dualistic constructions and self-enclosed ontological categories, also 
challenges the humanist tradition that maintains the human-animal dichotomy and mankind's supremacy over other species. Hence, their notion of becoming-animal comes forth as a conceptual tool to interfere with the hierarchical human-animal divide in Western thought, as well as a further attempt to unsettle fixed and stagnant identity categories. As such, becoming-animal involves "thinking in strange, fluid, unusual terms", a state of "becoming inhuman" (Deleuze, 1995, p. 11) by entering into an alliance or connection with animality. Thus, it necessarily involves "the relation of movement and rest of the animal particles or...the zone of proximity of the animal molecule" (Deleuze \& Guattari, 1987, p. 274). The notion of becoming-animal can also be conceived in terms of deterritorialization: a radical "movement by which 'one' leaves the territory" (Deleuze \& Guattari, 1987, p. 508). It is a progressive dislocation of the human subject from the domain of fixity, stability and identity, a metamorphic process that leads to an "absolute deterritorialization of the man" (Deleuze \& Guattari, 1986, p. 35). For Deleuze and Guattari (1987), in encountering the forces of animality, the human "enters into his or her becoming-animal" (p. 240), moving beyond all-too-familiar and strictly defined human territories. Hence, animal-becomings emerge as unique processes that "uproot one from humanity, if only for an instant" by undoing explicit forms of subjectivity (Deleuze \& Guattari, 1987, p. 240).

Correlatively, this process is neither a simplistic transfer from a fixed human identity to a stable animal identity, nor a course of resemblance or analogy. Deleuze and Guattari (1987) are 
clear that becoming-animal has nothing to do with representing or impersonating an animal: "it is not a question of imitating a horse, 'playing horse', identifying with one" (p. 258). Rather than mimicry or imitation, this notion delineates a more open-ended and transitional process that draws humans into dynamic contact zones, liminal passages or threshold states with their animal others. Indeed, "in an animal-becoming a man and animal combine, neither of which resembles the other, neither of which imitates the other, each deterritorializing the other", forming a "system of relay and mutations through the middle" (Deleuze \& Parnet, 2007, p. 50). Accordingly, this notion provides a mode of being "in-between" (Deleuze \& Guattari, 1987, p. 293) by introducing a state of indeterminacy, liminality and mutuality between these two ontological orders.

Deleuze's process-oriented ontology of becoming is also strictly correlated with his aesthetic approach to cinema. The principle of becoming, which is based upon the fluidity of transformation, is also associated with the mobility and changeability of the cinematic images: "the shot" is "becoming mobile itself" independent from the movement of the camera (Deleuze, 1997a, p. 25), due to the cinematic image's capacity to "replace, obliterate, and re-create the object itself" (Deleuze, 2001, p. 12). As a result, Deleuze (1997a) defines cinema first and foremost as the movement-image: "cinema does not give us an image to which movement is added; it immediately 
gives us a movement-image" (p. 2). In other words, as Felicity Colman details, "the image is a dynamic entity, as he shouts at us...'IMAGE = MOVEMENT'” (2011, p. 37).

In addition to detailing the dynamic features of the cinematic image, "Deleuze offers two basic propositions for critical screen analysis: the movement-image and the time-image" (Colman, 2011, p. 13-14). The movement-image depicts a montage regime that draws its strength from a successive and linear editing technique composed of relatively short-duration shots (Deleuze, 1997a). However, this array of shots is interfered with by some planned, arranged, emotive and shocking instants in order to produce a dramatic effect on the audience. These organized and agitating shocks, which arouse thinking mechanisms by rupturing "the sensory-motor links" (Deleuze, 1997a, p. 205), are named as "nooshocks" by Deleuze (2001, p. 156). The nooshocks involve explicit and director-oriented messages conventionally utilized in propaganda cinema (Deleuze, 1997a). On the other hand, the time-image is a technique constructed by the "dispersive...errant or wavering" editing of the long takes "working in blocs" (Deleuze, 2001, p. 1). In this editing technique, the emotive effect, which leads to the stimulation of thinking mechanisms, is produced by "irrational cuts": the intervals or gaps that reconcile "the continuity" of the film "with the sequence of irrational points, according to non-chronological time relationships" (Deleuze, 2001, p. 181). These cuts or intervals, which are created among the blocs 
of the long takes due to the wavering editing, provoke various new thoughts and emotions in the audience; they point towards the "unthought in thought" (Deleuze, 2001, p. 181).

According to this classification, the impulse-image is assessed in the cluster of the movement-image by Deleuze, since it reinforces the power of nooshocks by fetishizing the images through persistent repetitions (Deleuze, 1997a). The impulse-image, another Deleuzian concept on the aesthetics of cinema, focuses on the repetitive close-ups of partial objects. As such, "the object of the impulse is always the 'partial object', or the fetish" (Deleuze, 1997a, p. 128). These close-ups, particularly of faces, in turn, are converted into fetish objects or idol images through their recurrent employment (Deleuze, 1997a).

The notion of becoming-animal bridges the analysis between the narrative and the form of Kosmos, since the impulse-image - employed by Erdem throughout the movie in terms of facial close-ups - aims at deep and intense influence on the audience by revealing what is "prior to all differentiation between the human and the animal" (Deleuze, 1997a, p. 124). As such, the impulseimage is closely tied to the idea of becoming-animal, because impulse occurs in a milieu "where man" is "reunited with the originary world of animals" (Deleuze, 1997a, pp. 130-131). Hence, this image regime is accurately assessed by the Deleuzian film scholar David Deamer (2016) as the "actualisation of becoming-animal" (p. 203), since it inaugurates "the decomposition of a human 
foreground into an ahuman background" (p. 86). Following this overview of the crucial concepts from Deleuze and Guattari's philosophy, the next section explores the deployment of the idea of becoming-animal in the narrative of Kosmos, starting with discussing Erdem's close-ups on faces as a signifier of the zones of proximity or indiscernibility—liminal areas between humanity and animality.

\section{Becoming-Animal in the Narrative of Kosmos}

\section{Meta-Idea Conveyed Through the Close-ups: The Zones of Indiscernibility}

The idea of becoming-animal, as delineated earlier, is tied to the creation of dynamic zones of interaction that perforate the boundaries separating mankind from animals. In this fashion, it offers a way of being in the middle by "sweeping up the two distant... points, carrying one into the proximity of the other" (Deleuze \& Guattari, 1987, p. 293). Yet, in his monograph on the portraiture of the British painter Francis Bacon, Francis Bacon: The Logic of Sensation (2003), Deleuze further elaborates on the theme of becoming-animal. For him, many of Bacon's figures, through various bodily mutations and deformations, provide powerful visual manifestations of this concept. As such, Bacon discloses an animal-becoming of the body or the profound connectedness of these two species categories by painting "a zone of indiscernibility or undecidability between man and animal...the common fact of man and animal" (Deleuze, 2003, p. 21). 
In this book, Deleuze also discusses the parallels between the notion of becoming-animal and the face-head distinction. He indicates that the head displays "an animal spirit" (Deleuze 2003, p. 20), even if it is hidden by the face. The face upholds the man-animal binary, since it is a socially produced order that is decisive for the formation of human subjectivity: "although the head, even the human head, is not necessarily a face, the face is produced in humanity" (Deleuze \& Guattari, 1987, p. 170). To disrupt this binary opposition, Deleuze (2003) stresses the head rather than the face and underlines the meat as "the common zone of man and the beast, their zone of indiscernibility" (p. 23). For him, as a portrait painter, Bacon accomplishes to "dismantle the face, to rediscover the head or make it emerge from beneath the face" (Deleuze, 2003, pp. 20-21), so that "the head becomes the nonlocalized power of the meat" (Deleuze, 2003, p. 26). Within this scope, the meat emerges as the common underlying ground between the human and the animal, or an intervallic corporeal region wherein one can no longer be distinguished from the other. Contrary to the socially constructed aspect of the face, the meat under the head is shared by humans and animals; it thus constitutes a zone of proximity or undecidability that are common to both-an indistinct and liminal ontological area which undoes the hierarchic orders between living things. As Ronald Bogue (1996) aptly demonstrates, such undecidable zones, which obscure the forms between the man and the beast, are made visible in Bacon's "butcher-shop images of dismembered 
bodies and unspecified cuts of meat, the torso-become-rib-roast or the cheek-become-muttonchop" (p. 262).

One of the main threads running throughout Kosmos is the continuity or commonality between humans and animals. Erdem displays the animals of the town with unique and peculiar characteristics akin to humans. Yet, the continuity or affinity of humans and animals is primarily portrayed by Erdem's distinctive use of the transitions between montage sequences and other scenes. Throughout the movie, he recurrently ruptures the unity of animal faces by a series of extreme close-ups in line with Deleuze's (2003) statement on the face: "the face is a structured, spatial organization" (p. 20), and it "has a great future, but only if it is destroyed, dismantled" (Deleuze \& Guattari, 1987, p. 171). Erdem predominantly dismantles faces by employing the close-ups of the eyes of the animals in montage sequences, and in the process, discloses that they have emotions like the human characters of the movie. To illustrate, he focuses on the eye of an ox, first when it is living, then displays it as trembling when the animal is about to die in a slaughterhouse. The pain and anguish of animals caused by humans' cruel treatment of them, as well as the threat of being in a war zone, are conveyed to the audience via close-up shots. Through the disquieting sounds of the battle at the town's borders and the extreme close-ups of animal faces, it is communicated that animals also suffer from the brutal atmosphere of the ongoing war and the cruelty of humans. Erdem, therefore, reflects on the close affinity or proximity of animals 
and humans throughout Kosmos via divergent techniques, including the montage sequences composed of the faces or the facial parts of animals.
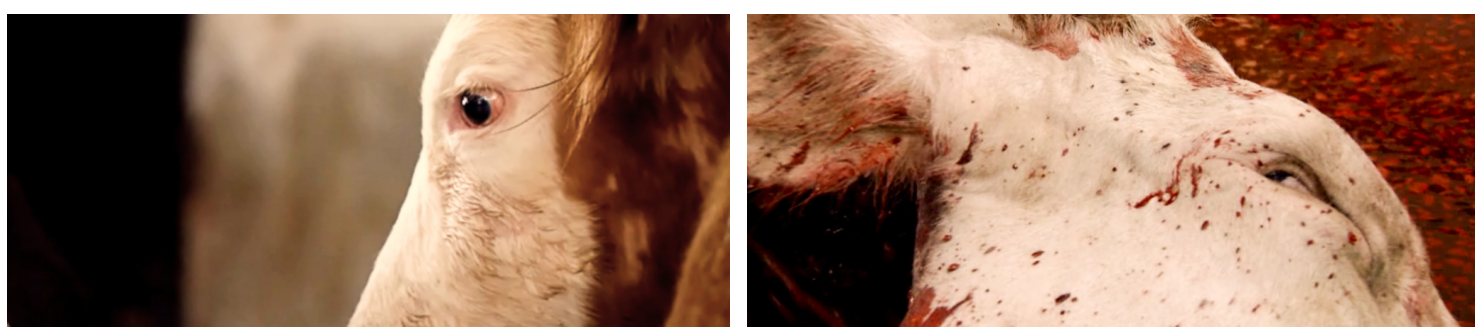

Figure 1. Film Stills from Kosmos (2009)

Erdem's editing of close-ups highlights the proximity and liminality between these two species in several other ways. The director matches the dramatic and poignant human expressions with the tormented faces or sorrowful eyes of the animals numerous times in the movie. For instance, after displaying Neptune's face with a medium close-up, when she is frustrated upon learning the intimate relationship between Kosmos and the newly arrived teacher, Erdem cuts to the face of an unsettling horse statue - a scene dubbed with a biting melody. In another example, he depicts Kosmos' curing of the tailor of the town, which is followed by his emotional cry through an over-the-shoulder close-up and a medium shot; then his camera cuts to an eye of a dead ox overlaid with blood. Similarly, when the police investigate Kosmos' residence due to his help to an unjustly slandered, innocent young man, Erdem makes a sudden transition to the trembling eye of the same agonal ox in the slaughterhouse. As such, the director frequently cuts to the faces of distraught people after presenting the eye of a suffering horse or an ox during the movie. The 
juxtaposition of the faces, as well as the depiction of the shared affective situations between humans and animals, in turn, emerge as a method to spotlight the zone of proximity or undecidability associated with the Deleuze-Guattarian idea of becoming-animal. Among the explicit juxtapositions of human and animal distress, one can also cite Erdem's portrayal of a dog fight following the shot that displays the fight among four brothers, or an escaping goose matched with the limping walk of the garrison commander's sister-in-law. All these overlapping scenes, in turn, recall the undecidable, liminal and interstitial zones, which are suggestive of "something shared or indiscernible" between humans and the rest of the animal kingdom (Deleuze \& Guattari, 1987, p. 273).
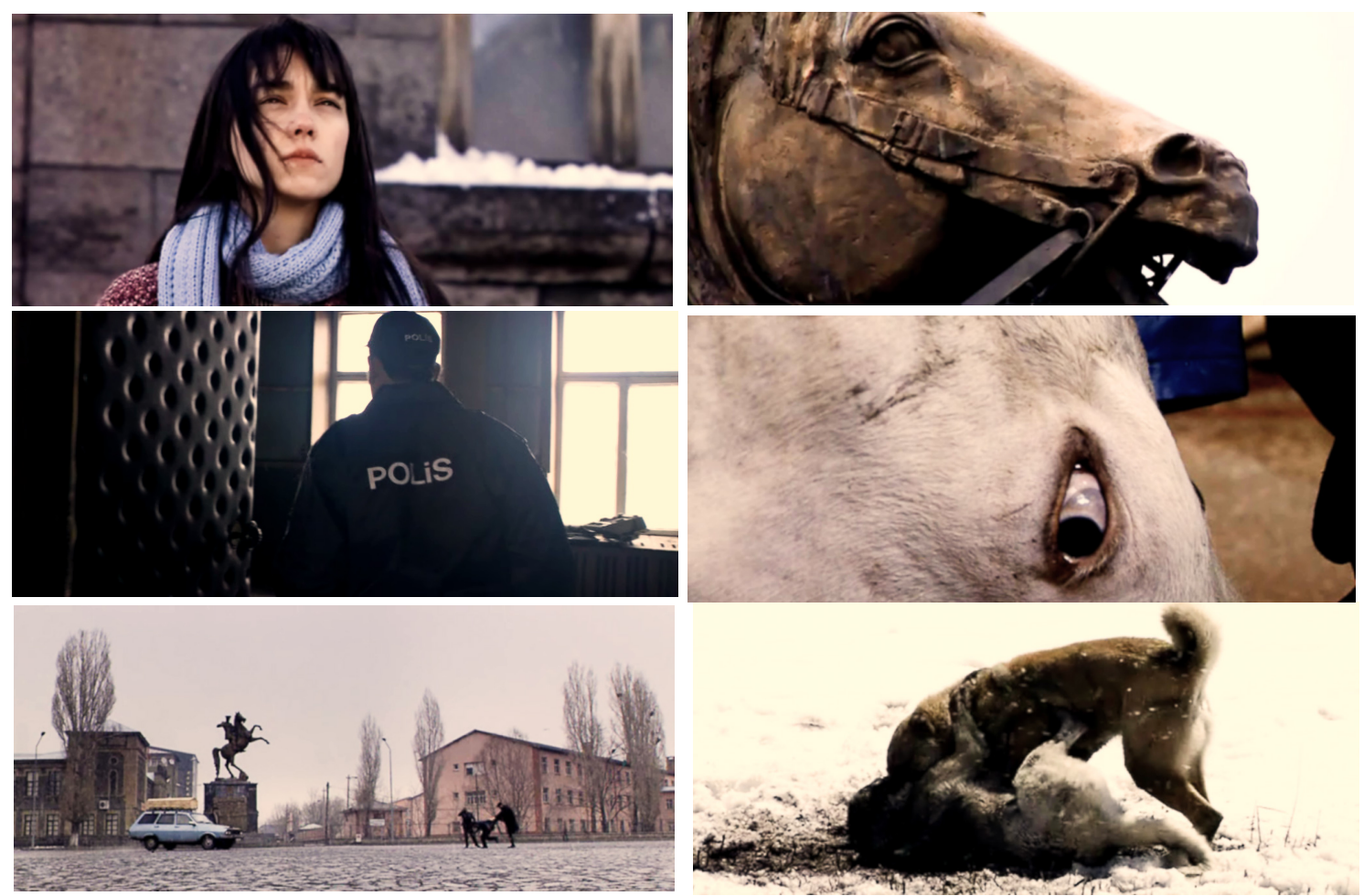

Figure 2. Film Stills from Kosmos (2009) 

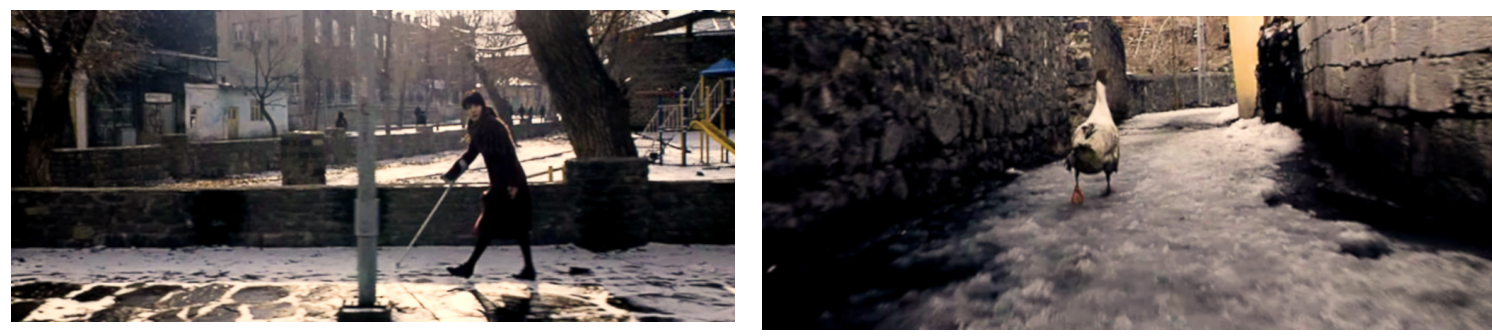

The shots that demonstrate the animals' reactions to the sounds of bombs and gunshotsincluding the fluttering and flitting of birds and geese-also recurrently take place in the movie. Hence, the discontent of the ill, weak and neglected people living amidst military threat due to the nearby combat is represented via the close-ups of the eyes of the terror-stricken, tormented animals and their stampedes, along with ominous sounds. As said earlier, Erdem constructs these types of juxtapositions by means of montage sequences, which are predominantly comprised of animal faces. These sequences, in turn, carry out two functions: they are dispersed into the movie to increase the emotional impact of the previous or the following cut as substantiated in the dog fight and residence investigation, while also connoting the meta-ideas of Kosmos-zones of indiscernibility that eliminate the sharp distinctions and hierarchical differences between human and animal existence.

Erdem's inclusion of a butcher character into the script-Yahya - is most probably an intentional choice to further emphasize the intermediary regions between humans and animals in the form of meat. By employing this character, the director shoots several sequences in the slaughterhouse. Almost all these sequences are accompanied by an agitating melody, involving the shots of the oxen's bloody body parts, their tissues being dragged on the ground, their heads 
without skin, the close-ups of their flesh, as well as Yahya's forcible behaviour on the animals. For instance, when Yahya washes his hands after a slaughter, the camera sharpens its focus on the skinless head of an inanimate ox while he is still in the frame. In addition to underlining the cruelty exercised on animals, the close-ups of the flesh and head display the common underlying structure between humanity and animality — the meat which suggests "an extreme proximity, an absolute contiguity" among these two seemingly separate ontological orders (Deleuze, 1997b, p. 78). They bear witness to a "ground", which for Deleuze and Guattari, "can dissolve forms and impose the existence of a zone in which we no longer know which is animal and which human, because something like the triumph or monument of their nondistinction rises up" (1994, p. 173). Echoing this perspective, Kosmos also talks about the cruelty of humans against animals while stressing their mutual fate: "what happens to them [animals] is because of human beings... since there is evil instead of justice. In fact, what happens to humans and animals is the same. They die in the same way. Mankind has no supremacy over animals" (Atay \& Erdem, 2009). In another sequence, when the teacher of the town blames Kosmos for abusing her due to their former sexual intercourse, she rhetorically asks: "what about the difference between the animal and the human?"-a question to which Kosmos replies as such: "there is no difference" (Atay \& Erdem, 2009). Hence, not only does Erdem evoke the idea of commonality among living things through his peculiar montage style, but he also continues to accentuate this theme through the statements of Kosmos and the 
presence of Yahya character in the narrative.
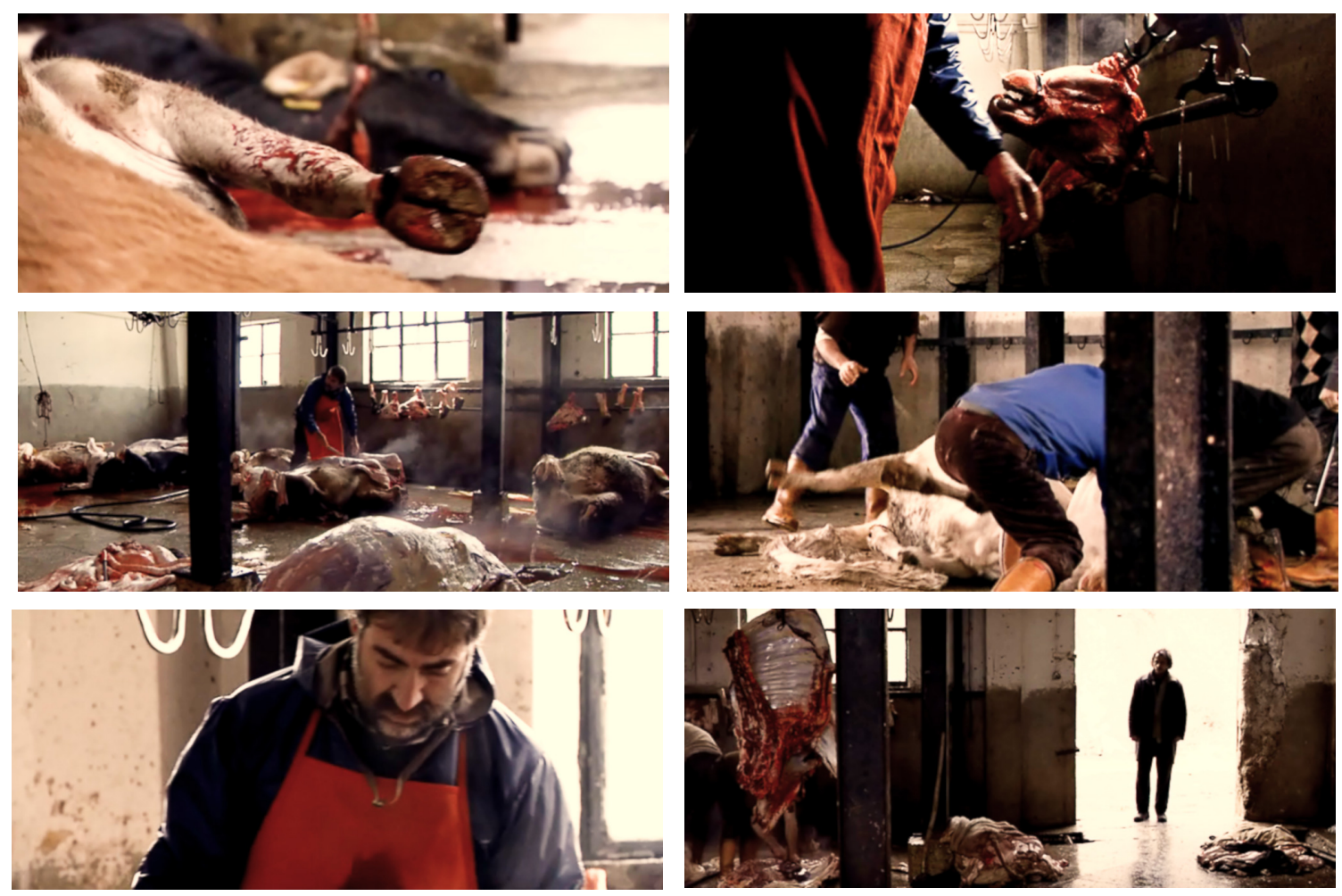

Figure 3. Film Stills from Kosmos (2009)

Becoming-animal is an intensive indiscernibility that both the human and the animal perform

in an area of coexistence "that makes it impossible to say where the boundary between the human

and animal lies" (Deleuze \& Guattari, 1987, p. 273). This area of coexistence, however, can also

be established within the language, through deterritorializing the means of human communication via disarticulation. As Deleuze and Guattari state in Kafka: Toward a Minor Literature (1986), in a literary becoming-animal, "there is no longer man or animal, since each deterritorializes the other, in conjunction of flux, in a continuum" (p. 22). Hence, this notion also signifies a divergence 
from the "order-word machine" (Deleuze \& Guattari, 1987, p. 514) of the language and leads to an intensification of human communication by opening it up toward its wider non-human potential, as in Kafka's animal stories. Correlatively, in Kosmos, Erdem further illustrates the potential of becoming-animal through the communication between Kosmos and Neptune, whereby they both transgress into an inhuman zone by stretching the boundaries of human language and expression.

The Inhuman Communication between Kosmos and Neptune

According to Deleuze and Guattari (1987), "the elementary unit of language, the statement, is the order-word" (p. 7). This structure provides a "power marker before it is a syntactical marker"; therefore, it "gives life orders" (Deleuze \& Guattari, 1987, p. 7). This ordered system of the language is an apparatus for forging fixed and rigidly defined human identities, because the "orderword machine overcodes language... and overcodes the body and head", creating "a machine of enslavement" (Deleuze \& Guattari, 1987, p. 514). Becoming entails a constant flow and transformation; thus, the fixed order of the language constitutes an obstacle against becomings. Nevertheless, it can be dismantled or loosened via disarticulated communication. Within this scope, Deleuze and Guattari (1986) astutely observe Franz Kafka's capability of broadening the limits of human communication through the establishment of a "minor literature" (p. 66) as a Prague Jew writing in German. For the authors, Kafka manages to push the boundaries of human 
language and thereby human subjectivity through his characters, particularly in The Metamorphosis wherein the main character "Gregor Samsa" engages in a process of "becominginsect" (Deleuze \& Guattari, 1986, p. 13). Through the inhuman transformations of Samsa, in this book, Kafka creates a novel and unprecedented form of communication that "blurs the resonance of words" (Deleuze \& Guattari, 1986, p. 6). Inhabiting an in-between area between man and animal deterritorializes the subject from the order-word structure of the language and opens the path for an intensive and transitory existence between humanity and animality. Hence, becoming-animal brings the human to a threshold of non-humanity through the deterritorialization of the human language, enunciation and articulation, a process also at work in Kosmos and Neptune's mode of communication.

The very first encounter of Kosmos and Neptune takes place by the riverside, where Kosmos calls her with a bird-like scream. Neptune replies to him in the same way, and they walk along the opposite sides of the river, while screaming with a liminal sound between human voice and a birdsong. Recalling Kafka's stories, they dismantle the order-word chain of the language and thereby their all-too-human subjectivities by remaining caught up in a process of becominganimal, or more precisely, becoming-bird. Through the intensity of these high-pitched, ambiguous screams - which transgress the boundaries of human speech and articulation - the audience can 
immediately grasp the love affair between the two. Yet, their communication implies less a mode of imitation than a passage or transition, whereby the sounds, voices and expressions of two different species continually slip and slide into each other. Hence, rather than striving to mimic or impersonate actual birds, Kosmos and Neptune attain a transitional and interstitial quality—one that breaks down the fundamental barriers between the human and the animal. Their inarticulate voices infuse their human territories with the particles of animal existence, and in the process, act as a means to intensify their communication. For instance, when Kosmos calls Neptune with a voice like birdsong, she can tell that it is him from tens of meters away. In this fashion, Kosmos and Neptune establish a more peculiar and profound connection by moving beyond the "rigid normativity" of the human language and expression (Colebrook, n.d.). In so doing, they reveal "an inhumanity immediately experienced in the body as such" (Deleuze \& Guattari, 1987, p. 273) or the "non-human becomings of man" (Deleuze \& Guattari, 1994, p. 169). Yet, the non-human becomings of these characters do not come to an end by their becoming-bird; instead, they are delineated in other modes of becoming in the subsequent sequences.

The Deleuze-Guattarian notion of becoming-animal "offers a robust account of intricacies" pertaining to "multispecies relationships" (Thiyagarajan, 2016, pp. 208-209). In line with this perspective, Erdem multiplies the manifestations of becoming-animal in the movie by forming different blocks of human-animal interaction, especially in the sequence that depicts the encounter 
of Kosmos and Neptune in the apartment given to the former by Yahya. As soon as their eyes meet, they run to each other grappling as dogs and twittering like birds. At this stage, there is no conversation between the two, but only a strange sound that oscillates between human voice and a woodnote, as well as deep breaths, howling and sniffing sounds. In the same sequence, Erdem also endows his characters with animal abilities, such as flying. By using nail polish, Kosmos first draws lines on his and Neptune's feet, an act which makes them look as if they have the claws of wild birds. Then, they begin to walk on the walls of the room like insects, while the articles on the shelves are flitting around. Subsequently, the audience witnesses a sense of flight or an abnormally rapid movement of Kosmos through the lens of Neptune's swiftly changing gaze on him, while they continue to shout at each other with bird-like voices. Yet, all these performative acts exceed simplistic analogy or mimesis; the lovers are neither trying to resemble any specific animal, nor pretending to be one. Their actions rather serve as a transformative force that draws into connection two distinct spheres, so that an odd mixture of human and animal is generated. Accordingly, the human identities of Neptune and Kosmos are brought to a liminal threshold between humanity and animality, to the "zone of proximity" with the "animal molecule" (Deleuze \& Guattari, 1987, p. 275), be it the molecule of birds, dogs or insects. This is a dynamic interpenetration which "is neither one nor two, nor the relation of the two; it is the in-between" (Deleuze \& Guattari, 1987, 
p. 293). These dynamic mixtures, proximities and in-betweens, in turn, entail the potential of "traversing human beings and sweeping them away" (Deleuze \& Guattari, 1987, p. 237). Hence, deterritorializing the fixed limits of the human language and subjectivity, the love affair between

Kosmos and Neptune constructs a novel and fluid form of expression that strongly resonates with Deleuze and Guattari's conception of the becoming-animal. At the end of the movie, Kosmos advances to the last stage of becoming — becoming-imperceptible—whereby he attains a complete dispossession of his human subjectivity by forming linkages with the rest of the living and nonliving constituents of the world.

\section{Kosmos' Flow Toward Imperceptibility}

According to Deleuze and Guattari (1987), becomings initialize with a process of becomingwoman, which is followed by an array of other becomings, including becoming-animal, -child, plant, -molecular and -imperceptible. Hence, the idea of becoming-imperceptible is formulated by the authors as "the immanent end of becoming, its cosmic formula" (Deleuze \& Guattari, 1987, p. 279). They further argue that "a fiber stretches from a human to an animal, from a human or an animal to molecules, from molecules to particles, and so on to the imperceptible" (Deleuze \& Guattari 1987, p. 249). Within this scope, becoming-imperceptible signals the most extreme form of becomings, since it refers to the disintegration of all kinds of categorical divides between human 
and non-human life processes. This notion entails one's openness towards the immanent potentialities of life via the creation of far-reaching relationships with the world. Correlatively, it is rightfully defined by Audrone Žukauskaite (2015) as "the creative power of life", which "dissolves the model of subjectivity" (p. 61) in order to "make a connection with the world, to connect and conjugate with its molecular components" (p. 66). Since becoming-imperceptible is achieved by an intense mode of interconnectedness of divergent life processes, it coincides with a total dispossession of identity, which can also be understood as a state of impersonality and preindividuality. At this impersonal and pre-subjective level, there are no longer clear-cut distinctions between self/other, human/non-human, man/nature, but rather a fluid and excessive mode of relationality that allows one to fuse with the rest of the universe. As Braidotti (2006a) usefully details, becoming-imperceptible is "the point of fusion between the self and his/her habitat, the cosmos as a whole" (p. 154). This view is also evident in Deleuze and Guattari's (1987) elucidation of the concept as a "becoming everybody/everything", since "becoming everybody/everything is to world, to make a world" (p. 280).

As an outsider, Kosmos already has a loose bond with his social identity, and he further loses his ties with his human identity by undergoing multiple processes of becoming-animal. Yet, toward the end of the movie, he fully leaves behind the perceptible boundaries of individuality or personal 
identity by merging with the rest of his environment. Erdem, first of all, develops and substantiates this theme through Kosmos' healing ability: when this abnormal dervish cures the disease in a patient's body, he inhales the invisible ill portion. During the process of healing, he feels the pain and suffering of the patient due to swallowing his/her disease. In these sequences, a fluid flow or passage is opened up between Kosmos and the patient. Once Kosmos licks and swallows the ill portions, he begins to cough and spit with so much pain that he cannot stand up from the place he falls for a while. Kosmos' curing ability, in turn, allows him to blend with the bodies of the afflicted people, incorporating their torment and agony into his sense of himself. Such a portrayal of healing begins to embody a process of becoming-imperceptible - a profound state of interconnectedness whereby Kosmos is dispossessed of his own unified and individual identity. It foregrounds the progressive fusion of self and other that brings about a relational embodied landscape and an attendant state of de-individualization and de-personalization.

Yet, the becoming-imperceptible of Kosmos is most acutely illustrated at the climax of the movie through his integration with the cosmos. In the final sequence, Kosmos tries to heal the garrison commander's ill sister, who is most probably suffering from a disorder in her spinal cord. As Kosmos licks her back, the commander bursts in on them, leading him to think that there is sexual intercourse between the two. Kosmos runs away against the reaction of the soldiers, while there is a stormy blizzard outside. While he is walking along on the masses of snow, he cries and 
screams as he does in the very beginning of the movie. At the same time, nature, with all its constituents, begins to lament along with Kosmos: the sounds of the screaming doves and curvetting horses, as well as the stampedes of bird herds and fluttering ducks, attest to his mergence with all entities of the universe. Erdem portrays Kosmos as such an integral part of his habitat that almost all of its elements suffer from his torment and misery - a theme highlighted by the disastrous sounds of nature. For Deleuze and Guattari (1987), becoming-imperceptible is "to reduce oneself to an abstract line, a trait, in order to find one's zone of indiscernibility with other traits, and in this way enter the...impersonality of the creator" (p. 280). Resonating with this view, Kosmos reaches the highest degree of imperceptibility and impersonality, a mode of "becomingeverybody/everything" (Deleuze \& Guattari, 1987, p. 280), whereby he is carried into an indiscernible zone with ill people, animals, and finally, the rest of the material world. The name Kosmos is most probably chosen deliberately for the main protagonist, as he accomplishes to amalgamate with the cosmos and all of its molecular components at the end of the film. In this fashion, all the becomings detailed so far reach a sort of limit-experience here, spreading to include all living and non-living things, and facilitating the immanent immersion of the human subject in various life processes - in "the profound life of all forms or all types of beings" (Deleuze \& Guattari, 1983, p. 4). 
As in the final sequence, Erdem employs the shocking instants of the impulse-images by repetitively juxtaposing humans and animals in the montage sequences throughout the film as well. Through these sequences, he predominantly dwells on the concept of becoming-animal, while chiefly applying the style of the impulse-image. Hence, the final section discusses the montage regime of Kosmos through the lens of the time-image and the impulse-image.

\section{Becoming-Animal in the Form of Kosmos Through Erdem's Dispersed Montage Sequences}

Throughout Kosmos, Erdem utilizes the long takes and wide shots commonly used in European art-house cinema except for the film's montage sequences. Hence, in this movie, his aesthetic approach displays an errant and changeable character with regard to the creation of emotive effect: it weds the arranged, planned and affective shocks of the movement-image applied in the montage sequences with the long takes of the time-image within a general framework of wavering editing. Erdem's montage style, in turn, shares some common features with the timeimage, yet, at the same time, he also practices a form of the movement-image: the impulse-image utilized as nooshocks due to the presence of deeply emotive and shocking close-ups. Therefore, this section considers the image regime of Kosmos as an innovated version of the impulse-image, while revealing the ties between the narrative and the form of the movie. 
Deleuze (1997a) relates the literary movement, naturalism to the impulse-image insofar as the impulse-image's function is to seize "fragments in the originary world" (p. 124). Naturalism, in other words, signifies becoming-animal since it employs the direct and pure effect of impulses, which reveal the originary milieu shared by the human and the animal (Deleuze, 1997a). Thus, for Deleuze (1997a), the impulse-images are "human animals" (p. 124), as the stylistic display of the facial close-ups in this regime yields a zone of undecidability that blurs the boundaries between man and animal. It is for this reason that this approach is characterized as the materialization of becoming-animal in editing by Deamer (2016). "Deleuze's film theory", in turn, as Jonathan Burt demonstrates, offers an important means for understanding "animal representation and its place within human-animal relations" (2006, p. 168).

Deleuze (1997a) further asserts that "the close-up is the face" and "the affection-image is the close-up" (p. 87). According to his cinema theory, the impulse-image is also classified in the cluster of the "affection-image" (Deleuze, 1997a) due to their commonality in the employment of facial close-ups; however, what differentiates the impulse-image from the affection-image is the obsessive and repetitive usage of these close-ups in order to prioritize them. This image regime, in turn, conveys impulses that create "an impression in the strongest sense" due to the empowerment of the images by their fetishized repetitions (Deleuze, 1997a, p. 123). 
Transposed to the discussion of Kosmos, Erdem converts the face and face units into "idols or fetishes" (Deleuze, 1997a, p. 125) through their repetitive and disquieting close-ups dispersed throughout the movie. Indeed, the long and wide takes prevalent in the film are frequently and abruptly interrupted by the montage sequences mainly comprised of the short-duration close-ups of the faces of animals or their facial parts. These sequences, in turn, act as emotive impulseimages that induce "pure" feelings in the audience, such as "visceral sensations, felt resonations, intensities" (Ashton, 2006, p. 126). For instance, after long takes, Erdem often cuts to the bloody eye of an ox trembling before death — a deeply affecting and distressing close-up that he recurrently employs earlier when the animal is alive. In this fashion, he enhances the affective impact of some sections of the plot by juxtaposing them with the subsequent montage sequences, while building up an emotional tension in the narrative through the dialectical balance between the long- and short-duration shots. As discussed earlier, Erdem also matches highly unsettling and extreme close-ups of animal faces with the dramatic and emotive human faces or situations throughout the movie. After the shot of the trembling eye of the ox, for example, he cuts to the worried face of Yahya, or soon after showing an emotional eye of a horse, he displays a badly beaten man by his three brothers. Accordingly, Erdem's fetishistic repetition of animal and human faces in the montage sequences not only amplifies the effect of the related shots, but it also alludes to the undecidable and indeterminate zones that make up the idea of becoming-animal. Besides creating 
an emotional tension, the transitions between the close-ups of animal and human faces yield a state

of liminality that blurs the lines between the two. These montage sequences, which function as impulse-images, in turn, act as a reminder of the non-human roots of humanity, resonating with "Deleuze and Guattari's positioning of the human within a broader notion of inhuman history" (Stark \& Roffe, 2015, p. 15).
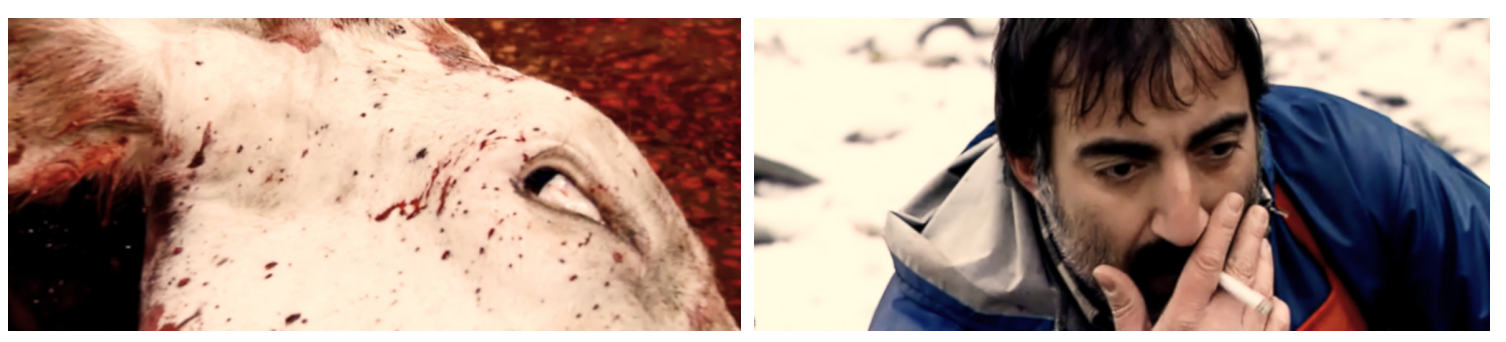

Figure 4. Film Stills from Kosmos (2009)

Yet, the pattern of montage sequences Erdem employs throughout Kosmos can also be considered as carrying the features of nooshocks and irrational cuts. In these sequences, the director creates explicit, direct and agitating nooshocks, which, for Deleuze (1997a), underline the shocking aspect of the impulse-image: "the law or the destiny of the impulse is to take possession through guile, but violently" (pp. 128-129) in order to stimulate thinking mechanisms. To illustrate, when Kosmos saves Neptune's drowning younger brother at the onset of the movie, he lays half-stunned with great pain, which is typical when he works miracles. Next, Erdem cuts to the eye of a horse demonstrated with a disconcerting background melody. In another scene, an ox 
is forcibly brought to a slaughterhouse with a disturbing horse neigh in the background; then, the animal's fall to the ground is shown in a montage sequence. All these sequences, in turn, serve as affect units in the movie since they consist of emotive impulses that display the features of nooshocks through their agitative intensity. It might also be claimed that these series of shots have comparable qualities to Deleuze's idea of irrational cuts or intervals, since they create gaps within the original flow of the plot without having any precise or coherent structure of their own. Yet, rather than attempting to generate new types of thoughts in the audience, or provoke the "unthought in thought" (Deleuze, 2001, p. 181), with these sequences, Erdem primarily directs the viewer to his own ideas related to the dissolution of the human-animal binary. Although some of these montage sequences are prolonged by slow-motion - which is an unconventional usage of the impulse-images and nooshocks - they still retain their shocking effect by violently interfering with the actual flow of the narrative and stimulating the audience with their tension and high emotions. As a result, these sequences appear as modified and unique versions of the impulse-images operating as nooshocks, within the context of Deleuze's image theory.

Ultimately, Kosmos can be said to bring into play a renewed interpretation of the impulseimage - a sub-category of the Deleuzian movement-image. This is because the impulse-images contained within the montage sequences have a significant capacity to interrupt the prevalent aesthetics of the film composed of the long takes associated with the time-image. As a consequence 
of applying the style of the impulse-image — which is understood as the attainment of becominganimal in editing_Erdem achieves a harmony between the form and the narrative of Kosmos.

\section{Conclusion}

This article delves into the complex narrative of the Turkish director Erdem's film Kosmos by setting up an encounter with the Deleuze-Guattarian philosophical concept of becoming, in particular becoming-animal. The movie illustrates the fluid and transformative nature of becoming by the agency of its leading character. Kosmos' uncommon mode of communication with Neptune is evaluated as a form of becoming-animal or becoming-inhuman whereby they pass into an animalistic state through exceeding the boundaries of human language and articulation. In addition, the paranormal healing power of the protagonist, which mobilizes a non-dualistic flow or passage between self and other, is interpreted as yielding a state of self-dispossession through which he begins to access the realm of imperceptible becomings. The immersion of Kosmos into the materiality of the world in the final sequence-wherein nature and its constituents accompany his anguish-is also recognized as the ultimate epitomization of the idea of becomingimperceptible. It is suggested that the theme of becoming-animal, which suspends all species categories and established dichotomies between humans and animals, is further mobilized or animated through the montage sequences of Kosmos. Indeed, these sequences have a decisive role 
in propagating emotions and highlighting the meta-ideas of the film: the inherent ties, affinities and commonalities humans have with their non-human others.

Correlatively, this article also analyzes the aesthetics of the movie, Kosmos, mostly by studying its montage sequences. The distinctive editing technique implemented by Erdem throughout the film displays the features of the Deleuzian impulse-image, mainly due to the montage sequences comprised of the recurrent and agitating close-ups of animal and human faces. These emotive montage sequences are embedded in and dispersed among the long takes of the time-image, which are employed to communicate the actual plot of the movie. They, in turn, act as shocking independent units, while amplifying the dramatic effect of the previous or subsequent shots. Hence, the montage regime of Kosmos carries the qualities of the impulse-image due to the fetishized repetitions of stimulating facial close-ups, although the aesthetics of the time-image is more dominant in the film in terms of duration. Since Erdem's employment of the impulse-image blurs the very boundary between human and animal existence, it also corresponds to the notion of becoming-animal in editing. Subsequently, this article demonstrates the singular deployment of the theme of becoming-animal both in the narrative and the form of Kosmos, revealing the consistency between the two. 


\section{Bibliography}

Akser, M. (2015). Turkish Independent Cinema: Between Bourgeois Auteurism and Political Radicalism. In D. Baltruschat \& M. P. Erickson (Eds.), Independent Filmmaking Around the Globe (pp. 131-148). Toronto: University of Toronto Press.

Altıntaş, G. (2014). Inbetweenness as a Mode of Resistance in Reha Erdem's Cinema. In M.

Akser \& D. Bayrakdar (Eds.), New Cinema, New Media: Reinventing Turkish Cinema (pp. 253-266). Newcastle: Cambridge Scholars Publishing.

Ashton, D. (2006). Using Deleuze: The Cinema Books, Film Studies, and Effect. Ph.D. dissertation. Retrieved from OhioLINK, Electronic Theses and Dissertations Center.

Atay, Ö. (Producer), \& Erdem, R. (Director). (2009). Kosmos [Motion picture].

Turkey: Atlantik Film.

Bogue, R. (1996). Gilles Deleuze: The Aesthetics of Force. In P. Patton (Ed.), Deleuze: A Critical Reader (pp. 257-269). Oxford: Blackwell.

Braidotti, R. (2001). Metamorphoses: Towards a Materialist Theory of Becoming. Cambridge: Polity Press.

Braidotti, R. (2006a). The Ethics of Becoming-Imperceptible. In C. V. Boundas (Ed.), Deleuze and Philosophy (pp. 133-159). Edinburgh: Edinburgh University Press. 
Braidotti, R. (2006b). Transpositions: On Nomadic Ethics. Cambridge: Polity Press.

Braidotti, R. (2011). Nomadic Theory: The Portable Rosi Braidotti. New York: Columbia University Press.

Burt, J. (2006). Morbidity and Vitalism: Derrida, Bergson, Deleuze, and Animal Film Imagery. Configurations, 14(1-2), 157-179. doi: 10.1353/con.0.0008

Colebrook, C. (n.d.). Only an Animal Can Save Us. Retrieved from https://www.academia.edu/19843390/Only_an_Animal_Can_Save_Us

Colman, F. (2011). Deleuze and the Film Concepts. Oxford, New York: Berg.

Deamer, D. (2016). Deleuze's Cinema Books: Three Introductions to the Taxonomy of the Images. Edinburgh: Edinburgh University Press.

Deleuze, G. (1995). Negotiations 1972-1990 (M. Joughin, Trans.). New York: Columbia University Press.

Deleuze, G. (1997a). Cinema 1: The Movement-Image (H. Tomlinson \& R. Galeta, Trans.). Minneapolis: University of Minnesota Press.

Deleuze, G. (1997b). Essays Critical and Clinical (D. W. Smith \& M. A. Greco, Trans.). Minneapolis: University of Minnesota Press.

Deleuze, G. (2001). Cinema 2: The Time-Image (H. Tomlinson \& R. Galeta, Trans.). London: The Athlone Press. 
Deleuze, G. (2003). Francis Bacon: The Logic of Sensation (D. W. Smith, Trans.). London:

Continuum.

Deleuze, G., \& Guattari, F. (1983). Anti-Oedipus: Capitalism and Schizophrenia (R. Hurley, M.

Seem \& H. R. Lane, Trans.). Minneapolis: University of Minnesota Press.

Deleuze, G., \& Guattari, F. (1986). Kafka: Toward a Minor Literature (D. Polan, Trans.).

Minneapolis: University of Minnesota Press.

Deleuze, G., \& Guattari, F. (1987). A Thousand Plateaus: Capitalism and Schizophrenia (B.

Massumi, Trans.). Minneapolis: University of Minnesota Press.

Deleuze, G., \& Guattari, F. (1994). What is Philosophy? (G. Burchell \& H. Tomlinson, Trans.).

London: Verso.

Deleuze, G., \& Parnet, C. (2007). Dialogues II (B. Habberjam \& H. Tomlinson, Trans.).

New York: Columbia University Press.

Roffe, J., \& Stark, H. (2015). Introduction. In J. Roffe \& H. Stark (Eds.), Deleuze and the Non/Human (pp. 1-16). London: Palgrave Macmillan.

Thiyagarajan, N. (2016). "Like Words Printed on Skin": Desire, Animal, Masks, and 
Multispecies Relationships in Monique Truong's The Book of Salt. In D. Herman

(Ed.), Creatural Fictions: Human-Animal Relationships in Twentieth and Twenty-First

Century Literature (pp. 193-217). New York: Palgrave Macmillan.

Žukauskaitè, A. (2015). Deleuze and Beckett Towards Becoming-Imperceptible. In S. E. Wilmer

\& A. Žukauskaite (Eds.), Deleuze and Beckett (pp. 60-77). London: Palgrave Macmillan.

\section{ENDNOTES}

${ }^{1}$ For a video example of the sequences in question, see: $\underline{\text { https://www.youtube.com/watch?v=7xXJ5601It8 }}$

${ }^{2}$ For a video example of the sequences in question, see: https://www.youtube.com/watch?v=Eg5-TR3mSRI 